\title{
Protecting the skin during thyroidectomy
}

\section{Protegendo a pele durante a tireoidectomia}

\author{
Renan Bezerra Lira'; Genival Barbosa de Carvalho'; José Guilherme Vartanian, ACbC-SP1; Luiz Paulo Kowalski, TCBC-SP1
}

A B S T R A C T

\begin{abstract}
In this note we describe the standard technical maneuver used in our department to protect the skin during thyroidectomy in order to get the best aesthetic result. We use surgical gloves to protect the skin during these operations to reduce the negative impact of thermal trauma and mechanical retractors and energy delivery devices at the edges of the skin incised. This practice is effective, inexpensive, rapid, reproducible and showed no complication in our experience of over 2,500 thyroidectomies.
\end{abstract}

Key words: Thyroidectomy. Surgical procedures, operative. Esthetics. Protection. Skin.

\section{INTRODUCTION}

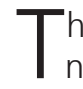
he history of modern thyroidectomy begins in the nineteenth century with Theodor Billroth (1829-1894). However, one of his disciples, Theodor Kocher (1841-1917), considered the "father of the thyroid surgery", was responsible for most of the development of the technique and the description of classical cervical "necklace" incision in 1898, which has had his name until today".

The well-differentiated carcinoma of the thyroid gland has had the fastest growing in incidence in recent years among all types of cancer. The incidence rates almost tripled in the last 30 years ${ }^{2}$. In Brazil, it is estimated that 10,590 new cases of thyroid cancer were diagnosed in women in 2012, it being the fourth most common malignancy in females ${ }^{3}$. In our department, between 2008 and 2010, 1,321 patients underwent operations on the thyroid (1,100 women) with a mean age of 44 years and $85 \%$ of cases below 60 years of age. In 2011 and 2012, 1,404 thyroidectomies were performed in the Department of Head and Neck Surgery. Since this is a disease that primarily affects women, especially below 60 years of age, the appearance of the neck scar is considered very important, and concern with cosmetic results of this surgical procedure is gaining prominence, with great intellectual and financial investment in the development of new techniques that result in smaller or less exposed, aesthetically favorable scars (transaxillary and posterior cervical access).

These new surgical techniques increase time and costs. Moreover, they cannot be applied in most cases. Therefore, it is essential to achieve the best cosmetic result in the classic open thyroidectomy scar, since the procedure is indicated for most patients. For this, several technical solutions have been proposed, such as prethyroid muscles section and thyroidectomy without detaching the skin flap ${ }^{4}$. Currently, conventional thyroidectomy is performed through an anterior necklace incision in the neck, two to three inches above the sternal notch, preferably on a natural neck fold or wrinkle, with a length ranging from four to six inches, depending on the anatomical characteristics of the patient (neck circumference) and the size of the gland to be removed ${ }^{4}$. In general, small incisions are more exposed to trauma by retractors or thermal injury by energy delivery devices, with a negative impact on the appearance of the resulting scar. Therefore, in addition to careful synthesis technique, protection of the the skin around the incision during the surgical procedure is mandatory, as well as the excision of the traumatized edges at the end of the process, if necessary ${ }^{5}$. In this context, several techniques or precautions can and have been used by head and neck surgeons in the attempt to avoid trauma or burns of the neck during thyroidectomy. In this article we describe a simple, rapid and inexpensive technique routinely used to protect the skin in our operations on the thyroid.

\section{SURGICAL TECHNIQUE}

After general anesthesia, the patient is positioned with a pad under the shoulder blades, in order to get cervical hyperextension. Antisepsis is performed and the surgical fields are placed. The modified Kocher cervical incision is planned and marked on the skin. Normally, this incision is located about $3 \mathrm{~cm}$ above the sternal notch,

1. Department of Head and Neck Surgery, AC Camargo Cancer Center, São Paulo - SP, Brazil. 
centralized, coinciding with a natural skin fold or wrinkle and 4 to $6 \mathrm{~cm}$ in length, depending on characteristics such as height, weight, neck circumference, distance between the cricoid and sternal notch, thyroid volume and need for emptying the central compartment of the neck. The skin is incised with a scalpel (15 blade) down to the subcutaneous tissue and then with electrocautery until the subplastimal plan, where skin flaps are dissected up to the cricoid, superiorly, and sternal notch, inferiorly, with careful hemostasis.

The skin protectors are made before the operation, from a pair of sterile powder free surgical gloves (Figure 1). The gloves are cut in the transition between the hand and wrist. The parts relating to the glove hands are discarded. In the gloves wrists, the previously cut edges are folded and then fixed to the previously sectioned platysma (one at the top and one at the bottom) with three inverted stitches at the bottom, three inverted stitches at the top and one stitch on each side, fixing the protectors to each other at the end of the incision. Only lateral stitches are visible during the operation (Figure 2). After this fixation on the edges of the incision, the free part of each skin protector is attached to the superior and inferior surgical fields, keeping the incised skin edges everted, protected and away.

Thyroidectomy is then performed in the usual way using retractors, monopolar, bipolar and ultrasonic electrocautery, as needed. After removal of the surgical specimen, we proceed to revision of hemostasis, placement of drains (if necessary) and suturing of pre-thyroid muscles in the middle region. The skin protectors are then loosened and removed. The closure continues with separate inverted sutures of 4-0 absorbable suture in the platysma and subcutaneous tissue, and intradermal continuous suture with 4-0 nylon in the skin. The dressing is made with sterile micropore tape forming a truss on the incision. Patients are instructed to keep the incision covered with silicone or micropore bandage for at least a month, changing it whenever necessary. To illustrate this technique and its results, we show a case of a 30-years-old woman with papillary thyroid carcinoma who underwent total thyroidectomy. All images in this article are from this patient and in figure 3 we can see the resulting scar ten and 45 days after the operation. This patient had no postoperative complications.

\section{DISCUSSION}

Theodor Kocher described the anterior cervical necklace incision in 1898, seeking the best aesthetic result in his time ${ }^{1,6}$. Since then, a huge technical evolution occurred in thyroidectomy, trying to achieve the best functional and aesthetic results, including smaller incision and scar. Currently there are at least 20 different surgical approaches to the thyroid gland ${ }^{7}$. However, smaller

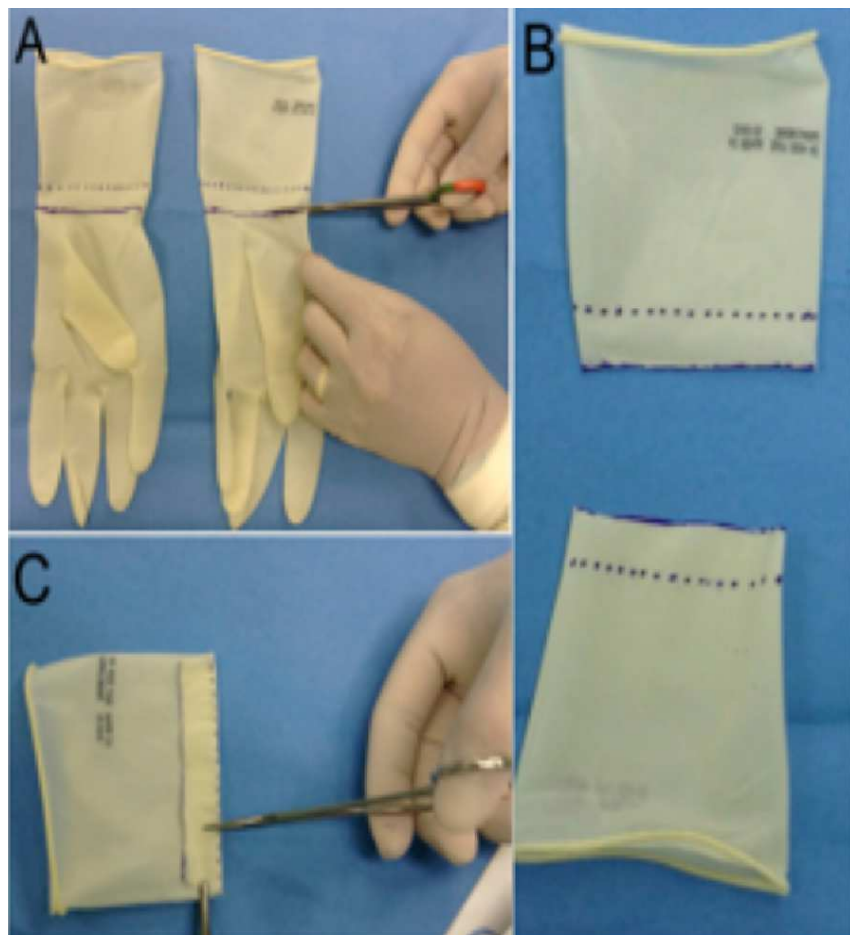

Figure 1 - Design and manufacturing of skin protectors using a pair of sterile surgical gloves. The gloves are cut in the transition between the hand and wrist $(A)$; the hand parts are discarded (B); at the gloves' wrists, the previously cut edge is folded (C).

incisions do not appear to have a direct impact on patients' aesthetic satisfaction. Bokor et al. compared minimally invasive approach with conventional open thyroidectomy and found no significant difference in terms of body image, beauty and self-confidence scores between groups ${ }^{5}$. Other studies showed no relationship between the relative or absolute length of the scar and satisfaction reported by patients, even in female patients, suggesting that the issue of satisfaction with the scar after thyroid operations is far more complex, involving several other factors beyond simply length of the scar ${ }^{8,9}$. In this context, the technical effort must be directed not only at making smaller incisions, but at trying to get an aesthetically more favorable scar, preventing hypertrophic and hyperchromic scars. Kim et al. analyzed the risk factors for hypertrophic scarring after thyroidectomy and showed that high body mass index, prominent sternocleidomastoid and small distance between the incision and the sternal notch were associated with a higher incidence of hypertrophic scars ${ }^{10}$. This study did not examine the trauma of skin edges during thyroidectomy as a potential risk factor for hypertrophic scarring. However, these and other authors have highlighted the importance of avoiding excessive retraction, trauma or thermal injury to the skin edges during the execution of the operation in order to achieve a better cosmetic result $4,5,8,10,11$

To our knowledge, there is only one formally published technique for skin protection in thyroid surgery. 


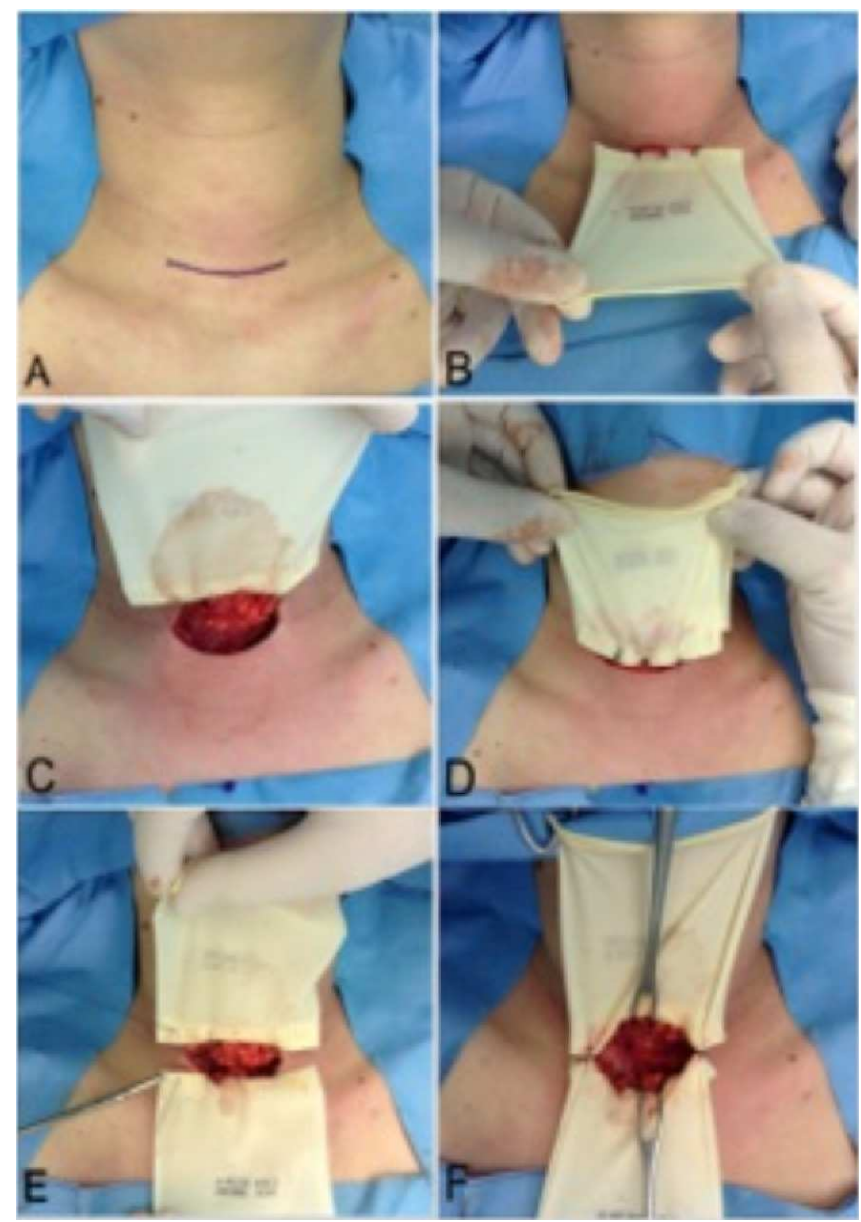

Figure 2 - Incision and fixation of skin protectors. Planning the incision (A); fixing the the upper and lower skin protectors with stitches $(B, C, D$ and $E)$; appearance after fixation of skin protectors (F).

Lee et al. described the use of Penrose drains to create envelope-shaped skin protectors, fixing them to the edges of the skin incision during thyroidectomy ${ }^{11}$. In Brazil, there are various unpublished surgical maneuvers, held at different institutions to avoid trauma to the skin edges of the incision during thyroid operation.

We here describe a standard practice for thyroid surgeries in our department, as for others, such as the

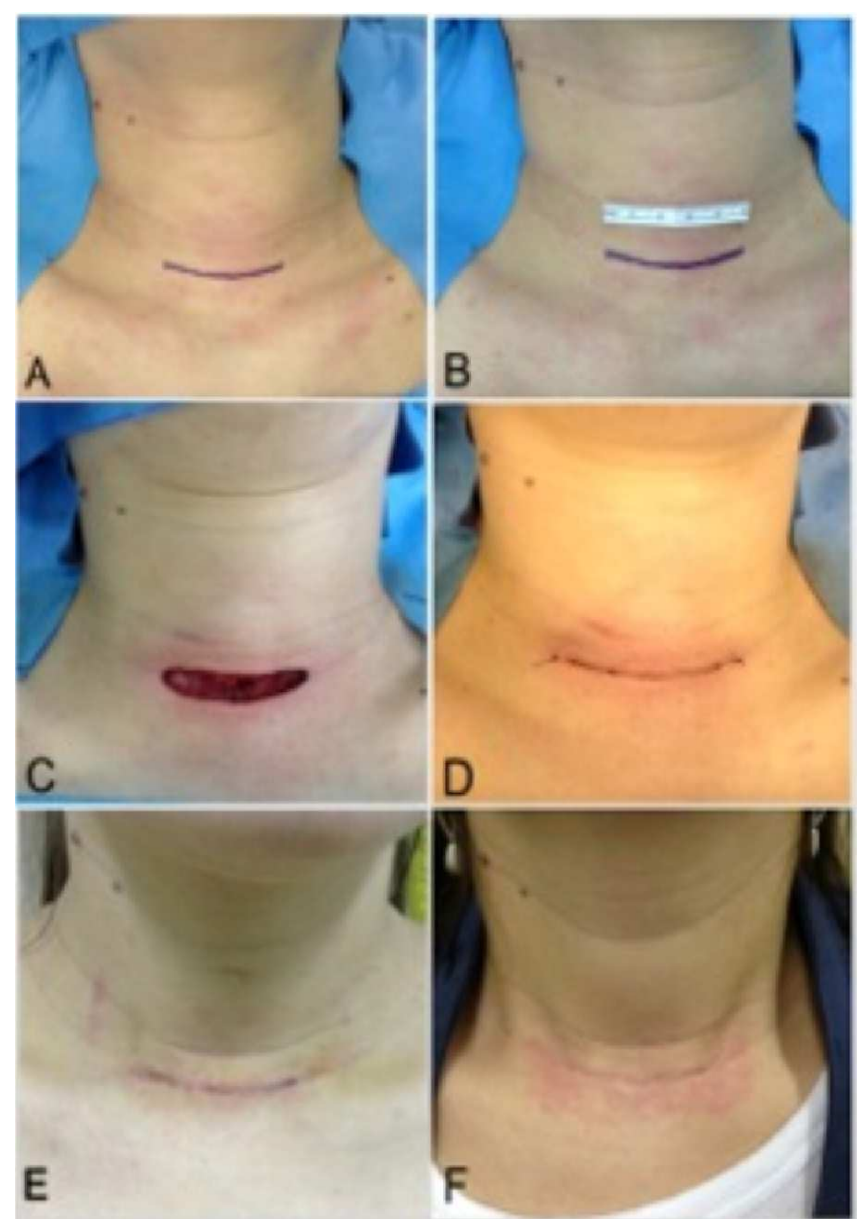

Figure 3 - Aesthetic result of thyroidectomy scar using the technique described for skin protection. Planning the incision ( $A$ and $B$ ); appearance of skin edges after removal of specimen (C) and after the end of the procedure $(D)$; resulting scar on the tenth $(E)$ and $45^{\text {th }}$ (F) postoperative days.

Sistrunk operation, cervical lymphadenectomy and submandibulectomy: the use of skin protectors made from surgical gloves in order to avoid thermal injury and trauma from retractors and energy delivery devices. This practice, which seems to improve the cosmetic results of the scar, is effective, inexpensive, rapid and reproducible and showed no complication in our experience of over 2,500 cases.

\section{R E S U M O}

Nesta nota descrevemos a manobra técnica padrão utilizada em nosso departamento para proteger a pele durante as tireoidectomias com o objetivo de obter o melhor resultado estético. Empregamos luvas cirúrgicas para proteger a pele durante estas operações objetivando diminuir o impacto negativo dos traumas térmico e mecânico de afastadores e dispositivos de entrega de energia nas bordas da pele incisada Esta prática é efetiva, barata, rápida, facilmente reprodutível e não mostrou nenhuma complicação em nossa experiência de mais de 2500 tireoidectomias.

Descritores: Tireoidectomia. Procedimentos cirúrgicos operatórios. Estética. Proteção. Pele. 


\section{REFERENCES}

1. Hannan SA. The magnificent seven: a history of modern thyroid surgery. Int J Surg. 2006;4(3):187-91.

2. Cramer JD, Fu P, Harth KC, Margevicius S, Wilhelm SM. Analysis of the rising incidence of thyroid cancer using the Surveillance, Epidemiology and End Results national cancer data registry. Surgery. 2010;148(6):1147-53.

3. Brasil. Ministério da Saúde. Instituto Nacional de Câncer José Alencar Gomes da Silva. Estimativa 2012: Incidência do câncer no Brasil [Internet]. Rio de Janeiro: INCA, 2011. Acessado em: 26 de maio de 2013. Disponível em: http://www.inca.gov.br/estimativa/2012/ estimativa20122111.pdf

4. Consorti F, Milazzo F, Notarangelo M, Scardella L, Antonaci A. Factors influencing the length of the incision and the operating time for total thyroidectomy. BMC Surg. 2012;12:15.

5. Bokor T, Kiffner E, Kotrikova B, Billmann F. Cosmesis and body image after minimally invasive or open thyroid surgery. World $J$ Surg. 2012;36(6):1279-85.

6. Economopoulos KP, Petralias A, Linos E, Linos D. Psychometric evaluation of Patient Scar Assessment Questionnaire following thyroid and parathyroid surgery. Thyroid. 2012;22(2):145-50.

7. Yeung $\mathrm{GH}$. Endoscopic thyroid surgery today: a diversity of surgical strategies. Thyroid. 2002;12(8):703-6.

8. Toll EC, Loizou P, Davis CR, Porter GC, Pothier DD. Scars and satisfaction: do smaller scars improve patient-reported outcome? Eur Arch Otorhinolaryngol. 2012;269(1):309-13.
9. O'Connell DA, Diamond C, Seikaly H, Harris JR. Objective and subjective scar aesthetics in minimal access vs conventional access parathyroidectomy and thyroidectomy surgical procedures: a paired cohort study. Arch Otolaryngol Head Neck Surg. 2008;134(1):8593

10. Kim JH, Sung JY, Kim YH, Lee YS, Chang HS, Park CS, et al. Risk factors for hypertrophic surgical scar development after thyroidectomy. Wound Repair Regen. 2012;20(3):304-10.

11. Lee YS, Kim BW, Chang HS, Park CS. Use of a silicone penrose drain to protect incised skin edges during thyroid surgery. Surg Innov. 2013;20(4):NP1-2.

Received on 01/09/2012

Accepted for publication 15/11/2012

Conflict of interest: none.

Source of funding: none.

\section{How to cite this article}

Lira RB, Carvalho GB, Vartanian JG, Kowalski LP. Protegendo a pele em tireoidectomia. Rev Col Bras Cir. [periódico na Internet] 2014;41(1). Disponível em URL: http://www.scielo.br/rcbc

Address for correspondence:

Renan Bezerra Lira

E-mail: renan.lira@accamargo.org.br 